\title{
NOTA
}

\section{RELAÇÃO ENTRE O CONHECIMENTO LOCAL, ATRIBUTOS QUÍMICOS E FÍSICOS DO SOLO E USO DAS TERRAS ${ }^{(1)}$}

\author{
Luiz Arnaldo Fernandes ${ }^{(2)}$, Paulo Sérgio do Nascimento Lopes ${ }^{(2)}$, Santos \\ D’Angelo $^{(3)}$, Carlos Alberto Dayrell ${ }^{(4)} \&$ Regynaldo Arruda Sampaio ${ }^{(2)}$
}

\begin{abstract}
RESUMO
O conhecimento dos agricultores sobre o uso das terras pode auxiliar no levantamento de solos. Este trabalho foi realizado na Fazenda Americana, Norte do Estado de Minas Gerais, com o objetivo de relacionar o conhecimento local do ambiente com os atributos químicos e físicos do solo e com o Sistema de Capacidade de Uso das Terras para fins de reforma agrária. Por meio do conhecimento local, foram identificados sete ambientes: baixada, vereda, chapada, tabuleiro, carrasco, tabuleiro misto e espigão. $O$ conhecimento local sobre o uso das terras mostrou estreita relação com o Sistema de Capacidade de Uso, constituindo uma ferramenta para o parcelamento das terras para fins de reforma agrária.
\end{abstract}

Termos de indexação: Uso das Terras, reforma agrária, etnopedologia.

\section{SUMMARY: LOCAL KNOWLEDGE AS RELATED TO CHEMICAL AND PHYSICAL SOIL ATTRIBUTES AND LAND USE}

The knowledge of farmers about the use of land can assist in soils survels. This study was conducted on the Fazenda Americana, located in northwester Minas Gerais State, Brazil, to relate the local knowledge of the environments to soil chemical and physical attributes and to the Land Use Capacity System, with an Agrarian reform focus. Based on the local knowledge seven environments were identified: baixa, vereda, chapada, tabuleiro, carrasco, tabuleiro misto and espigão (terms roughly translatable as: lowland, palm swamp, plateau, tableland, tall shrubland, mixed tableland and range top land). The local knowledge of environments is closely related with the Land Use Capability Classes, and represents a tool for the partitioning of land for Agrarian reform.

Index terms: Land Use Capability Classes, agrarian reform, ethnopedology.

\footnotetext{
(1) Trabalho financiado pelo Instituto Nacional de Colonização e Reforma Agrária, Superintendência Regional 06. Recebido para publicação em julho de 2007 e aprovado em fevereiro de 2008.

(2) Professor do Instituto de Ciências Agrárias, Universidade Federal de Minas Gerais -UFMG, Caixa Postal 135, CEP 39404-006 Montes Claros (MG). E-mail: larnaldo@ufmg.br

${ }^{(3)}$ Professor do Departamento de Biologia da Universidade Estadual de Montes Claros, CEP 39400-000 Montes Claros (MG). Email: santosdangelo@gmail.com

(4) Engenheiro Agrônomo, Centro de Agricultura Alternativa do Norte de Minas Gerais, Rodovia Haroldo Tourinho, 4095, CEP 39400-000 Montes Claros (MG). E-mail: carlosdayrell@gmail.com
} 


\section{INTRODUÇÃO}

O Estado de Minas Gerais elaborou, pioneiramente, a legislação ambiental específica para definir e tornar obrigatório o licenciamento ambiental para projetos de assentamentos rurais do Instituto Nacional de Colonização e Reforma Agrária (INCRA), por meio da Deliberação Normativa 44 do Conselho Estadual de Política Ambiental (COPAM), publicada em 25 de novembro de 2000 , data em que entrou em vigor. A partir dessa data, a exigência do licenciamento ambiental nos projetos de assentamento rural de reforma agrária transformou a maneira de implementação e instalação dos assentamentos rurais do INCRA no Estado de Minas Gerais. A Deliberação Normativa trouxe consigo nova concepção de projetos de assentamento rural, que ultrapassa a clássica concepção de reforma agrária como sinônimo de divisão de terra, passando a significar também a garantia da conservação e preservação ambiental, constituindo um dos instrumentos operacionais de reabilitação do território e da difusão de práticas de controle ambiental adequadas aos contextos geoambientais e sociais das áreas de instalação da reforma agrária. Em 2005, esta deliberação foi aperfeiçoada e substituída pela Deliberação Normativa 88, referendada em 10 de dezembro de 2005.

A partir da publicação da Deliberação Normativa 44 do COPAM, o INCRA, por meio da Superintendência Regional 06 (SR 06) do Estado de Minas Gerais, contratou equipes multidisciplinares de profissionais para a realização dos estudos ambientais. Esses estudos foram feitos de forma participativa com todos os envolvidos, considerando o imaginário social em que as pessoas reproduzem sua forma de perceber o mundo, assim como as sensações que demonstram sobre os acontecimentos, tendo em vista sua subjetividade (Trindade \& Laplatine, 1997).

No que se refere aos solos, o Sistema Brasileiro de Classificação de Solos (Embrapa, 1999), segundo Correia (2005), não considera os saberes dos agricultores, os quais geralmente dispõem de bom acúmulo de informações sobre a evolução temporal da paisagem e do solo da região onde vivem. Segundo Krasilnikov \& Tabor (2003), as técnicas mais sofisticadas desenvolvidas pela pesquisa pedológica não são capazes de tornar o mapeamento detalhado, no nível da área das comunidades rurais, uma ferramenta para subsidiá-las na organização de seu espaço rural, uma vez que não é capaz de expressar a diversidade de solos utilizada pelos agricultores. Os diversos tipos de uso do solo (agrícola, artesanato, construção, etc.) permitem aos agricultores conhecer uma variabilidade desse recurso natural impossível de ser expressa nos levantamentos detalhados. Dessa forma, o saber local pode ser uma referência útil no levantamento de informações de solos, auxiliando no planejamento do uso da terra (Correia, 2005).
A região Norte do Estado de Minas Gerais apresenta restrições à agricultura familiar, onde o uso de técnicas é restringido pelas limitações financeiras. A baixa fertilidade dos solos e a deficiência hídrica foram motivos para que a agricultura familiar desta região desenvolvesse um conhecimento muito particular sobre as especificidades e potencialidades de cada unidade da paisagem. Esse conhecimento deve ser utilizado com vistas em promover assentamentos de reforma agrária, instigando novas formas de utilização das terras e, conseqüentemente, ampliando as possibilidades de uso de áreas com limitações agroambientais, tais como as do semi-árido mineiro. Para tanto é importante o reconhecimento agroecológico de territórios em termos de conhecimento local.

Os sertanejos, conhecidos na região por barranqueiros, vazanteiros, caatingueiros e gerazeiros, distinguem vários ambientes na paisagem do Norte de Minas Gerais, que, aparentemente, mostra-se monótona e uniforme, fazendo complexas associações entre gênese, qualidade e restrições de uso dos diferentes ambientes da paisagem. Segundo Costa (2006), barranqueiros são as pessoas que habitam as margens do Rio São Francisco, enquanto vazanteiros são todos aqueles que vivem nas vazantes de outros rios da região. Os caatingueiros ocupam os locais de mata seca e os gerazeiros habitam os planaltos, as encostas e os vales do bioma Cerrado (Costa, 2006).

O objetivo do presente trabalho foi relacionar o conhecimento que a população local tem do ambiente com os atributos químicos e físicos do solo e com o Sistema de Capacidade de Uso das Terras a fim de melhor subsidiar a divisão das glebas para fins de reforma agrária.

\section{MATERIAL E MÉTODOS}

\section{Localização da área de estudo}

O Projeto de Assentamento (PA) onde foi realizado o trabalho é denominado PA Americana e está localizado no município de Grão-Mogol, norte do Estado de Minas Gerais, cujas coordenadas geográficas são $16^{\circ} 17^{\prime} 55$ " S de latitude e $43^{\circ} 17^{\prime} 41$ " W de longitude. A Fazenda Americana, hoje denominada por PA Americana, com área de 18.102,1 ha, foi explorada até a década de oitenta com a produção de carvão a partir da vegetação nativa. Na época de realização dos estudos ambientais, a vegetação nativa encontrava-se em regeneração.

\section{Aspectos gerais da região e do Projeto de Assentamento Americana}

As terras do Projeto de Assentamento (PA) Americana eram de propriedade da Empresa Florestas Rio Doce, subsidiária da Companhia Vale do Rio Doce 
S.A., que nas décadas de setenta e oitenta, aproveitando-se dos incentivos para estabelecimento do pólo florestal em Minas Gerais, adquiriu grandes extensões de terras na região para o plantio de eucalipto. A partir de 1997, a empresa iniciou um processo para se desfazer de parte de suas terras por meio de leilões. Esses leilões foram questionados por movimentos ligados à reforma agrária, desencadeando um debate sobre a destinação das terras públicas e privadas em poder das reflorestadoras. Neste contexto, o Sindicato dos Trabalhadores Rurais de Grão-Mogol - MG reivindicou para fins de reforma agrária as terras da Fazenda Americana. Em atendimento a essa reivindicação, o INCRA realizou uma vistoria e declarou que as terras não eram aptas para assentamento rural da reforma agrária. Não concordando com o parecer do INCRA, o Sindicato dos Trabalhadores Rurais de Grão-Mogol - MG, juntamente com outros movimentos ligados à reforma agrária, propôs nova vistoria com a participação da organização não-governamental Centro de Agricultura Alternativa do Norte de Minas Gerais. Em setembro de 1999, foi realizada nova vistoria que concluiu ser viável a desapropriação, desde que se adotasse uma forma de exploração agroextrativista, fundamentada na preservação ambiental dos Cerrados. Em junho de 2002, tiveram início os estudos para a obtenção do licenciamento ambiental e elaboração do projeto de parcelamento. Neste período, 70 famílias de semterras da região ocuparam a Fazenda Americana.

O projeto de parcelamento foi elaborado em dez meses e, durante todas as etapas, houve o envolvimento e a participação dos agricultores e extrativistas da região, que já estavam ocupando a fazenda e de outros que vislumbravam a posse de um lote no PA Americana. Dos agricultores e extrativistas que participaram do processo de elaboração do projeto de parcelamento, $51 \%$ eram da zona rural de municípios cuja vegetação nativa é a de Cerrado, $27 \%$ de municípios onde o Cerrado faz transição com a mata seca e $22 \%$ de municípios de Caatinga típica.

As superfícies aplainadas que formam a maior parte do relevo do PA Americana são constituídas de recobrimento de material argilo-arenoso, provavelmente do Terciário, sobre rochas predominantemente quartzíticas do Pré-Cambriano, com relevo predominantemente ondulado, forte ondulado e montanhoso (Embrapa, 1979). A classe de solo predominante no município de Grão Mogol, segundo Embrapa (1979), é Latossolo Vermelho-Amarelo álico A moderadotextura média fase Cerrado subcaducifólio relevo suave ondulado.

A vegetação original mais comum é o Cerrado subcaducifólio e suas formações afins, campo Cerrado e altimontano, mata seca e formações transicionais para a Caatinga nas bordas de terrenos mais férteis (Embrapa, 1979). Verifica-se razoável ocorrência de sempre-vivas (Paepalanthus ssp.), bem como de pequenas formações de veredas isoladas, com uma freqüência discreta de buritizeiros (Mauritia flexuosa), de espécies endêmicas, como o cactos (Discoacactus horstii), de ocorrência única no planeta, e de canelasde-ema (Vellozia sp.), de grande importância ecológica (Viana et al., 2004).

Segundo Viana et al. (2004), as características climáticas do município de Grão-Mogol são muito variáveis, abrangendo climas subúmido a semi-árido e fracamente semi-árido. O índice médio pluviométrico é de $1.182 \mathrm{~mm}$ com chuvas concentradas no período de outubro a março, quando são registradas chuvas que atingem $80 \%$ do total anual precipitado. A temperatura média é de $21,5^{\circ} \mathrm{C}$. Ainda segundo o autor, as principais feições de relevo correspondem à Serra Geral, localmente conhecida por Serra da Bocaina, e às superfícies aplainadas. A altitude varia de 600 a $1.344 \mathrm{~m}$, sendo a maior altitude verificada na Serra Geral. Na área do PA Americana, a altitude média é de $800 \mathrm{~m}$.

Levantamento de informações sobre o uso das terras e caracterização dos diferentes ambientes junto aos agricultores extrativistas

Foi levantado um conjunto de informações etnoecológicas junto aos agricultores e extrativistas, recorrendo-se às perspectivas metodológicas desenvolvidas por Dayrell (1998) em estudos pioneiros sobre os "gerazeiros" no Norte de Minas. Também foram realizadas visitas as propriedades vizinhas ao PA para conhecer os sistemas produtivos e obter informações da região junto aos moradores locais.

Todas as 70 famílias de sem-terras que ocupam as terras do PA Americana, cujas origens foram descritas anteriormente, participaram do estudo. Inicialmente, foi feito o reconhecimento da área do PA pelos agricultores e extrativistas em imagens de satélite (TM-LANDSAT-5) fornecidas pelo INCRA SR 6. Em seguida, a partir do mapa com o perímetro da área e rede hidrográfica do PA (Figura 1), os agricultores e extrativistas construíram a primeira versão da distribuição dos ambientes, com as respectivas descrições (Figura 2).

Após a familiarização dos ambientes reconhecidos e descritos pelos agricultores e extrativistas e pelos técnicos, foram selecionados seis agricultores e extrativistas mais experientes para acompanhar os técnicos nos trabalhos de campo para identificação, descrição e delimitação dos diferentes ambientes reconhecidos.

Levantamento dos atributos edáficos e ambientais para a classificação dos ambientes segundo o Sistema de Capacidade de Uso das Terras

Após a confecção do mapa georreferenciado com os ambientes reconhecidos pelos agricultores e extrativistas, foram levantadas informações (profundidade efetiva dos solos, drenagem, 


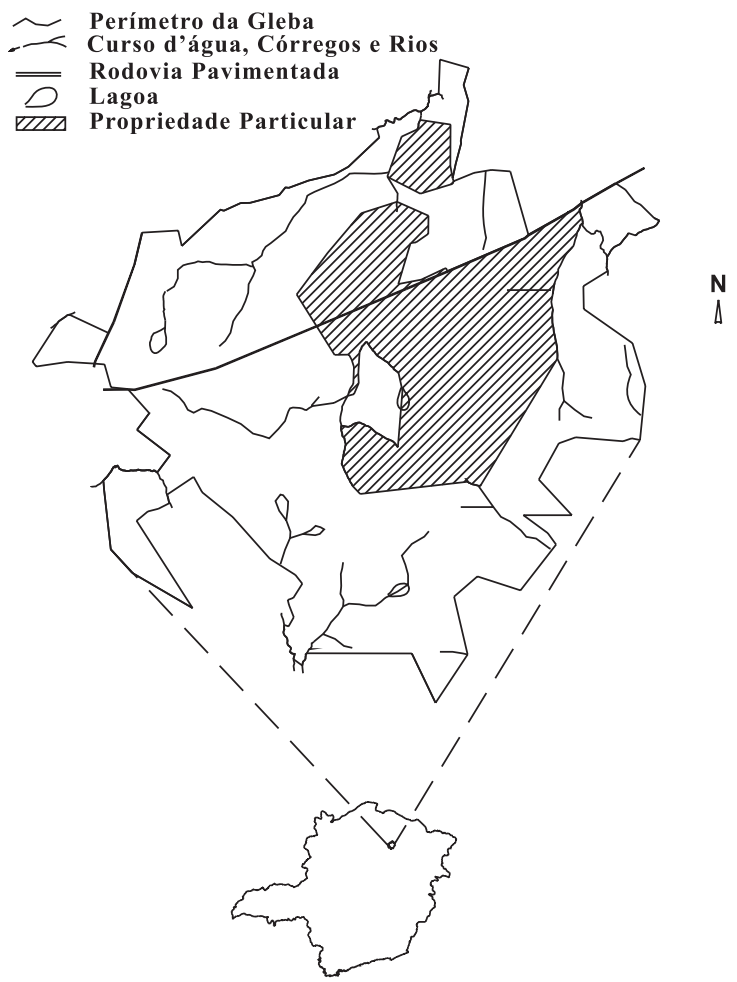

Figura 1. Localização aproximada da área estudada, no Estado de Minas Gerais e detalhes do perímetro e rede hidrográfica do Projeto de Assentamento Americana.

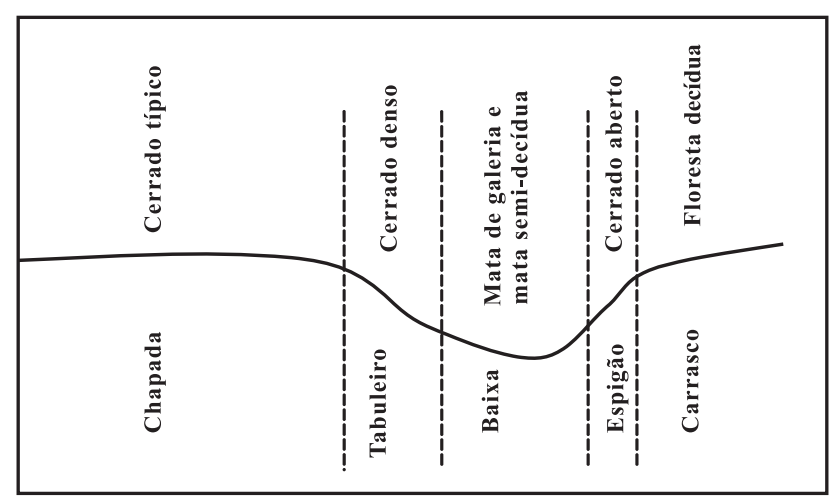

Figura 2. Esquema da posição dos diferentes ambientes na paisagem reconhecidos pelos agricultores e extrativistas, com as respectivas vegetações.

pedregosidade, risco de inundação, declividade do terreno, presença ou risco de erosão hídrica, cor, textura e saturação por bases das camadas superficiais dos solos) para a classificação das terras no Sistema de Capacidade de Uso, conforme Lepsch (1983) e Bertolini \& Bellinazzi Júnior (1994). As amostras de solos para as análises químicas e físicas foram coletadas em duas camadas, 0-20 e 20-40 cm de profundidade, num mesmo local, utilizando-se de um trado do tipo holandês.
As amostras compostas de cada profundidade foram constituídas pela homogeneização de 2 a 14 amostras simples, conforme o tamanho e homogeneidade da área de cada ambiente. As amostras compostas analisadas por ambiente e por profundidade foram assim discriminadas: baixada, 10; vereda, 12; chapada, 23; tabuleiro, 18; carrasco, 11; tabuleiro misto, 8, e espigão, 7 amostras compostas. As análises químicas e físicas para os atributos $\mathrm{pH}$ em água, $\mathrm{P}$ extraível e $\mathrm{P}$ remanescente, $\mathrm{Ca}, \mathrm{Mg}, \mathrm{K}$ e Al trocáveis, $\mathrm{H}+\mathrm{Al}$ extraível, matéria orgânica, granulometria da fração terra fina (areia total, silte e argila), foram realizadas conforme Embrapa (1997). Com base nestes atributos, calcularam-se, ainda segundo Embrapa (1997), os atributos soma de bases (SB), CTC efetiva (t), CTC a pH 7 (T), saturação por bases (V) e saturação por alumínio $(\mathrm{m})$. Após a análise química e física dos solos, calcularam-se a média e o desvio-padrão das propriedades analisadas, sendo os resultados interpretados de acordo com Alvarez V. et al. (1999). A partir das informações dos agricultores e extrativistas e dos resultados das análises químicas e físicas, as terras foram classificadas de acordo com o Sistema de Capacidade de Uso (Lepsch et al., 1983; Bertolini \& Bellinazzi Júnior, 1994).

O mapa dos ambientes identificados pelos agricultores e extrativistas e o de parcelamento das terras foram digitalizados em base planialtimétrica fornecida pelo INCRA SR 6. Os SIGs utilizados para a digitalização e organização das informações geradas foram os Sistemas ARC-INFO, ArcView, ESRI ILWIS (ITC) e SGI-VGA (Engespaço).

\section{RESULTADOS E DISCUSSÃO}

Reconhecimento dos ambientes pelos agricultores e extrativistas e uso das terras

Foram reconhecidos sete ambientes: baixa ou baixada, vereda, chapada, tabuleiro, carrasco, tabuleiro misto e espigão. Na figura 2, é esquematizada uma seqüência dos ambientes no extremo oeste do PA, construída por meio da técnica da caminhada transversal, que consistiu em percorrer determinada área do PA com os agricultores e extrativistas, observando todos os ambientes existentes. Dayrel (1998) e Correia (2005), em trabalhos realizados no Norte de Minas Gerais, encontraram denominações semelhantes às atribuídas para os ambientes com os mesmos atributos do PA Americana.

A baixa ou baixada localiza-se em depressões do terreno, que, no período chuvoso, formam lagoas, e ao longo dos cursos d'água (Figura 2). Atualmente, as lagoas acumulam água apenas no período das chuvas e os cursos d'água são de regime intermitente ou efêmero. Segundo os moradores da região, até à década de oitenta, as lagoas permaneciam com água durante todo o ano e a maioria dos cursos d'água era permanente. 
A vegetação predominante no interior das lagoas no período das secas é a de gramíneas. Nas bordas dessas antigas lagoas e nas margens dos cursos d'água, observou-se vegetação de maior porte. As principais espécies vegetais identificadas foram: Pombeiro (Tapirira guianensis), Sangra-d'agua ou Croton (Croton urucurana) e Tamanqueira (Pera glabrata). O relevo varia de plano a suave ondulado e as camadas superficiais dos solos são de colorações que variam do preto ao cinza-claro. A baixa, segundo os agricultores e extrativistas, graças à sua maior fertilidade e melhor umidade, é terra de cultura e pode ser utilizada, por exemplo, para o cultivo de arroz, mandioca e hortaliças, praticamente durante todo o ano.

A vereda, segundo os agricultores e extrativistas, ocorre ao longo dos cursos d'água e difere da baixa por ser um ambiente menos úmido, com as camadas superficiais dos solos de colorações amareladas e mais arenosas. O relevo é suave ondulado e a vegetação predominante é a de coquinho azedo (Butia capitata), muito explorado pelos agricultores e extrativistas e comercializados no mercado local para a fabricação de suco. As áreas de vereda, semelhantemente às da baixa, segundo a interpretação dos agricultores e extrativistas, podem ser utilizadas para pastagens, culturas anuais e algumas hortaliças, porém num período mais curto que o da baixa, tendo em vista a menor disponibilidade de água às plantas no período das secas.

A chapada caracteriza-se por uma vegetação de Cerrado típico e ocorre nas partes mais altas da paisagem. O relevo varia de plano a ondulado, as camadas superficiais dos solos são de colorações avermelhadas e não apresentam pedregosidade. As principais espécies vegetais reconhecidas pelos agricultores e extrativistas foram: Sucupira-preta (Bowdichia virgilioides), Pau-terra (Qualea grandiflora), Imbiruçu (Eriohteca pubescens), Gonçalo-Alves (Astronium fraxinifolium), Tingui (Magonia pubescens), Cabeça-de-negro (Annona crassiflora), Caviuna (Dalbergia miscolobium), Pequizeiro (Caryocar brasiliense), Murici (Byrsonima collolobifolia) e Mamuda (Zanthoxylum riedelianum). Segundo os agricultores e extrativistas, as terras da chapada não são boas para a agricultura, podendo ser utilizadas para a criação extensiva de animais, chamada, regionalmente, de "solta", e para o extrativismo de frutos nativos, óleos, fibras, plantas medicinais, madeira e lenha.

O tabuleiro consiste de uma vegetação de Cerrado mais denso que o da chapada, localizado entre a chapada e a baixa ou entre a chapada e a vereda. A declividade do terreno varia de 5 a $15 \%$ e as camadas superficiais dos solos são de colorações avermelhadas. As espécies vegetais predominantes são: Angico (Anadenanther colubrina), Caraíba (Simarouba versicolor), Gonçalo-Alves (Astronium fraxiniflora), Mangaba (Harnconia speciosa) e Pequi (Caryocar brasiliense).
Segundo os agricultores e extrativistas, os atributos dos solos e a vegetação que ocorrem no tabuleiro indicam solos de melhor fertilidade. O tabuleiro é o local mais indicado pelos agricultores e extrativistas para a construção das moradias, quintais com espécies frutíferas e hortaliças irrigadas. Também recomendam o tabuleiro para o cultivo de algumas espécies perenes adaptadas às condições de baixa disponibilidade de água do solo, criação de pequenos animais e pastagens.

Em alguns locais de relevo mais acidentado que 0 da chapada, com declividade do terreno variando de 5 a $10 \%$, de solos mais férteis e com as camadas superficiais de colorações avermelhadas, a posição na paisagem que seria ocupada pela vegetação de chapada dá lugar a uma vegetação arbórea densa de pequeno diâmetro do caule, denominada carrasco. Nesse ambiente, as principais espécies vegetais reconhecidas foram: Pau-preto (Schinopsis brasilienses), Aroeira (Miracrodron urundeuva) e o Angico vermelho (Anadenathera colubrina).

Entre a baixa e a vereda ou entre esta e o carrasco pode ocorrer o tabuleiro misto. O tabuleiro misto em relação ao tabuleiro típico anteriormente descrito é mais estreito, com relevo mais acidentado e com espécies do carrasco que disputam o domínio do território com as do tabuleiro típico, como a Periquiteira (Acacia polyphyta) e o Surucucu (Piptadaenia viridiflora).

Embora considerem os solos do carrasco como sendo de boa fertilidade, extrativistas e agricultores salientam que tais solos apresentam baixa disponibilidade de água às plantas durante períodos de seca prolongada. Em decorrência da baixa disponibilidade de água, recomendam para as áreas do carrasco usos semelhantes aos da chapada.

O espigão ocorre na transição de relevo da paisagem e caracteriza-se por uma vegetação de gramíneas com algumas espécies herbáceas, declividade do terreno variando de 5 a $45 \%$, ocorrência de pedregosidade e solos com camadas superficiais de colorações avermelhadas. Localiza-se entre a baixa e o carrasco, onde, em alguns locais, ocorre o tabuleiro misto. Os agricultores e extrativistas não recomendam o uso destas terras para a agricultura, podendo ser utilizadas para a solta dos animais. A principal espécie vegetal reconhecida foi a Canela-de-ema (Vellosia sp.), uma planta herbácea.

O relevo do terreno, a umidade do solo, a vegetação e a cor das camadas superficiais dos solos foram os atributos mais utilizados para a diferenciação dos ambientes. Segundo Haridasan (1992), fatores edáficos, tais como: profundidade efetiva, presença de concreções no perfil, proximidade do lençol freático, drenagem, fertilidade e características físicas dos solos, são os fatores determinantes da fisionomia, composição florística, fitossociologia e produtividade dos ecossistemas naturais. 
Houve consenso entre os agricultores e extrativistas onde se inicia e termina determinado ambiente, como se houvesse uma linha imaginária demarcando-os (Figura 3). Segundo os agricultores e extrativistas, os atributos supracitados determinam o uso do solo e sua capacidade em manter a produtividade por anos consecutivos de cultivos, antes do pousio. Segundo Dayrell (1998), a lógica de ocupação dos terrenos pelos gerazeiros segue uma estratégia de multiusos das diferentes unidades da paisagem, explorando suas potencialidades e respeitando os seus limites, numa interação complexa, fundamental para a sua sobrevivência.

\section{Atributos do solo e classificação das terras no Sistema de Capacidade de Uso}

A partir dos resultados das análises físicas e químicas e dos demais atributos dos solos (Quadros 1, 2 e 3), as terras foram classificados de acordo com o Sistema de Capacidade de Uso (Lepsch, 1983; Bertolini \& Bellinazzi Júnior, 1994). Além dos atributos específicos de cada ambiente, para a classificação das terras foi considerado o clima da região, em que a estação seca ultrapassa quatro meses. Exceto no ambiente baixa e vereda, o cultivo de espécies perenes só pode ser feito com o auxílio de irrigação, a não ser no caso de espécies adaptadas às condições de baixa disponibilidade de água no solo. Os solos do ambiente chapada, por serem mais arenosos que os dos demais ambientes, apresentam, teoricamente, em anos normais de precipitação pluviométrica, menor disponibilidade de água para as plantas nos horizontes superficiais - seca edafológica (Lepsch, 1983).

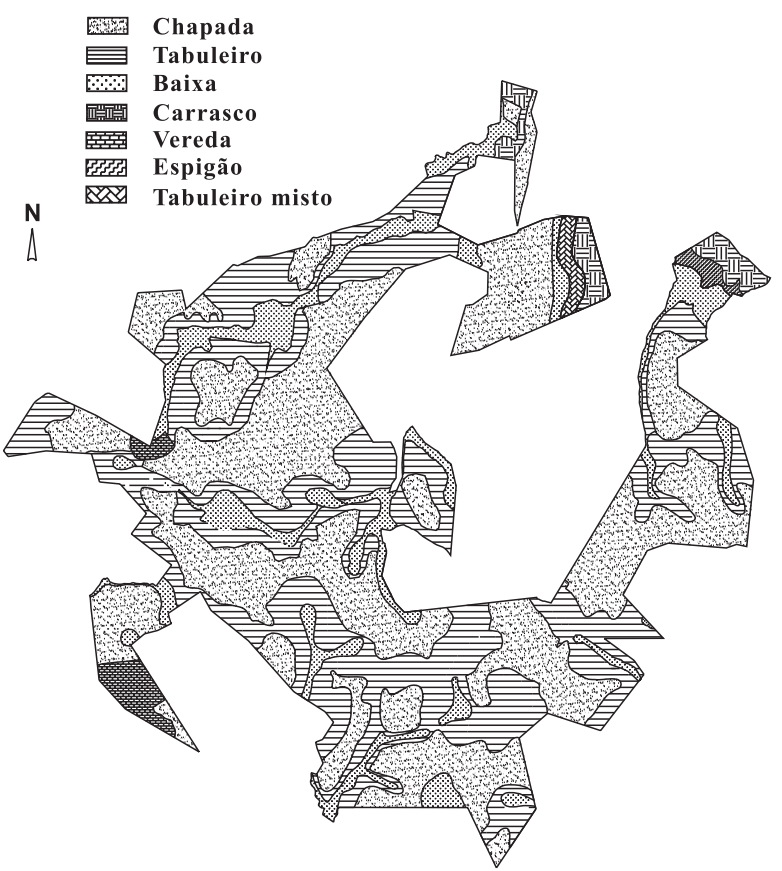

Figura 3. Distribuição dos diferentes ambientes reconhecidos pelos agricultores e extrativistas no Projeto de Assentamento Americana.
Para o ambiente de baixa ou baixada, verifica-se que, embora classificados como eutróficos (saturação por bases superior a $50 \%$, conforme Embrapa, 1999), os solos apresentam baixa disponibilidade de $\mathrm{P}$, textura média e bom teor de matéria orgânica (Alvarez V. et al., 1999).

De acordo com os quadros 1 e 3 , as terras do ambiente baixa no sistema de capacidade de uso foram classificadas como IIc - terras passíveis de utilização com culturas anuais, perenes, pastagem, reflorestamento e vida silvestre, com ligeiras limitações climáticas ocasionadas pela seca prolongada. Embora apresente limitações pelo excesso de água no período chuvoso, com freqüência de inundação entre um a cinco anos de recorrência e com duração de um a dois meses (informações fornecidas pelos moradores da região), esse ambiente é o mais intensivamente cultivado na região. Por outro lado, a menor profundidade do lençol freático, o elevado teor de matéria orgânica e a textura média dos solos desse ambiente garantem a disponibilidade de água às plantas durante quase todo o ano.

$\mathrm{O}$ termo vereda utilizado pelos agricultores e extrativistas da região refere-se a uma denominação microrregional e não a formações fitoecológicas caracterizadas pela presença de buritis (Mauritia flexuosa) e pindaíbas (Xylopia emarginata) da região dos Cerrados. No ambiente vereda, os solos são provenientes de deposições fluviais, com teores de matéria orgânica e de argila menores que os da baixa, são eutróficos e com baixa disponibilidade de $\mathrm{P}$ (Quadro 1). A vegetação foi classificada como um mosaico constituído por vegetação de Cerrado e floresta semi-decídua (Scolforo \& Carvalho, 2006), antropizada. As terras do ambiente vereda, de acordo com o Sistema de Capacidade de Uso, foram classificadas como IIIc - terras passíveis de utilização com culturas anuais, perenes, pastagem, reflorestamento e vida silvestre, com moderadas limitações climáticas resultantes, no caso, da seca prolongada.

Tanto o ambiente de baixa quanto o de vereda são áreas consideradas de preservação permanente (Resolução n 303, de 20 de março de 2002, do Conselho Nacional do Meio Ambiente, que dispõe sobre características, definições e limites de Áreas de Preservação Permanente), mas, em muitas propriedades rurais do Norte de Minas, são as únicas que permitem a sobrevivência da agricultura familiar. Segundo Neumann \& Loch (2002), a configuração de um desenvolvimento sustentável aponta para a necessidade de criar mecanismos e instrumentos de gestão ambiental, que sejam não só capazes de dar respostas aos problemas ambientais, em sintonia com o contexto social, econômico e agroecológico em que estes se manifestam, mas também sejam adequados às diferentes categorias e atores sociais presentes no meio rural.

$\mathrm{Na}$ chapada, também conhecida na região por Gerais, os solos são mais arenosos que os dos demais 
Quadro 1. Atributos químicos e físicos dos solos dos ambientes baixa, vereda e chapada, na camada de 0-20 e 20-40 cm de profundidade

\begin{tabular}{|c|c|c|c|c|c|c|c|c|c|c|c|c|}
\hline \multirow{2}{*}{ Atributo do solo } & \multicolumn{4}{|c|}{ Baixa } & \multicolumn{4}{|c|}{ Vereda } & \multicolumn{4}{|c|}{ Chapada } \\
\hline & \multicolumn{2}{|c|}{$0-20 \mathrm{~cm}$} & \multicolumn{2}{|c|}{$20-40 \mathrm{~cm}$} & \multicolumn{2}{|c|}{$0-20 \mathrm{~cm}$} & \multicolumn{2}{|c|}{$20-40 \mathrm{~cm}$} & \multicolumn{2}{|c|}{$0-20 \mathrm{~cm}$} & \multicolumn{2}{|c|}{$20-40 \mathrm{~cm}$} \\
\hline pH em água & $5,3^{(1)}$ & $\pm 0,8^{(2)}$ & 5,1 & $\pm 0,5$ & 5,8 & $\pm 0,6$ & 5,1 & $\pm 0,5$ & 4,5 & $\pm 0,3$ & 4,5 & $\pm 0,4$ \\
\hline$P\left(\mathrm{mg} \mathrm{dm}^{-3}\right)$ & 1,1 & $\pm 0,2$ & 1,0 & $\pm 0,3$ & 2,8 & $\pm 0,1$ & 2,2 & $\pm 0,3$ & 1,0 & $\pm 0,2$ & 1,0 & $\pm 0,2$ \\
\hline $\mathrm{Ca}\left(\mathrm{mmol}_{\mathrm{c}} \mathrm{dm}^{-3}\right)$ & 33,0 & $\pm 8,5$ & 30,0 & $\pm 7,6$ & 17,0 & $\pm 6,3$ & 14,0 & $\pm 5,7$ & 13,0 & $\pm 4,5$ & 8,0 & $\pm 6,4$ \\
\hline $\mathrm{Mg}\left(\mathrm{mmol}_{\mathrm{c}} \mathrm{dm}^{-3}\right)$ & 17,0 & $\pm 5,6$ & 10,0 & $\pm 6,5$ & 15,0 & $\pm 7,1$ & 11,0 & $\pm 15,3$ & 5,0 & $\pm 17,4$ & 4,0 & $\pm \quad 18,2$ \\
\hline $\mathrm{K}\left(\mathrm{mmol}_{\mathrm{c}} \mathrm{dm}^{-3}\right)$ & 1,8 & $\pm 0,4$ & 2,0 & $\pm 0,7$ & 1,1 & $\pm 0,6$ & 0,8 & $\pm 0,6$ & 0,9 & $\pm 0,4$ & 1,0 & $\pm 0,2$ \\
\hline $\mathrm{Al}\left(\mathrm{mmol}_{\mathrm{c}} \mathrm{dm}^{-3}\right)$ & 3,0 & $\pm 0,3$ & 0 & $\pm 0,2$ & 1,0 & $\pm 0,3$ & 1,0 & $\pm 0,4$ & 16,0 & $\pm 0,3$ & 11,0 & $\pm 0,4$ \\
\hline $\mathrm{H}+\mathrm{Al}\left(\mathrm{mmol}_{\mathrm{c}} \mathrm{dm}^{-3}\right)$ & 29,0 & $\pm 9,8$ & 21,0 & $\pm 7,5$ & 22,0 & $\pm 6,9$ & 18,0 & $\pm 8,6$ & 43,0 & $\pm 7,8$ & 26,0 & $\pm 4,5$ \\
\hline $\mathrm{SB}\left(\mathrm{mmol}_{\mathrm{c}} \mathrm{dm}^{-3}\right)$ & 51,8 & $\pm 15,2$ & 42,0 & $\pm 18,3$ & 33,1 & $\pm 12,4$ & 25,8 & $\pm 14,3$ & 18,9 & $\pm 16,4$ & 13,0 & $\begin{array}{r}+14,7 \\
\end{array}$ \\
\hline $\mathrm{t}\left(\mathrm{mmol}_{\mathrm{c}} \mathrm{dm}^{-3}\right)$ & 54,8 & $\pm 16,3$ & 42,0 & $\pm 17,2$ & 34,1 & $\pm 15,4$ & 26,8 & $\pm 17,6$ & 34,5 & $\pm 18,2$ & 24,0 & $\pm 14,8$ \\
\hline $\mathrm{m}(\%)$ & 0,6 & $\pm 0,1$ & 0 & 0 & 2,9 & $\pm 2,4$ & 3,7 & 0 & 46,0 & $\pm 7,9$ & 46,0 & $\pm 8,1$ \\
\hline $\mathrm{T}\left(\mathrm{mmol}_{\mathrm{c}} \mathrm{dm}^{-3}\right)$ & 80,8 & $\pm 27,8$ & 63,0 & $\pm 13,0$ & 55,1 & $\pm 14,8$ & 43,8 & $\pm 21,2$ & 61,9 & $\pm 12,4$ & 39,0 & $\pm 14,2$ \\
\hline $\mathrm{V}(\%)$ & 64,0 & $\pm 19,4$ & 67 & $\pm 15,6$ & 60,0 & $\pm 17,9$ & 59,0 & $\pm 16,3$ & 31,0 & $\pm 12,3$ & 33,0 & $\pm 11,2$ \\
\hline Mat. Org. (g kg $\left.{ }^{-1}\right)$ & 69,0 & $\pm 16,5$ & 45,0 & $\pm 18,9$ & 25,0 & $\pm 20,1$ & 15,0 & $\pm 18,4$ & 19,0 & $\pm 4,6$ & 10,0 & $\pm 2,1$ \\
\hline Areia $\left(\mathrm{g} \mathrm{kg}^{-1}\right)$ & 600,0 & $\pm 35,5$ & 560,0 & $\pm 58,8$ & 600,0 & $\pm 40,5$ & 580,0 & $\pm 53,7$ & 740,0 & $\pm 64,6$ & $700,0 \pm$ & $\pm \quad 45,2$ \\
\hline Silte $\left(\mathrm{g} \mathrm{kg}^{-1}\right)$ & 140,0 & $\pm 45,9$ & 160,0 & $\pm 25,2$ & 180,0 & $\pm 35,4$ & 200,0 & $\pm 30,2$ & 100,0 & $\pm 20,3$ & $120,0 \pm$ & $\begin{array}{r}+22,3 \\
\end{array}$ \\
\hline Argila $\left(\mathrm{g} \mathrm{kg}^{-1}\right)$ & 260,0 & $\pm 30,5$ & 280,0 & $\pm 32,3$ & 220,0 & $\pm 30,8$ & 220,0 & $\pm 28,9$ & 160,0 & $\pm 28,5$ & $180,0 \pm$ & $\pm 28,4$ \\
\hline
\end{tabular}

(1) Média . ${ }^{(2)}$ Desvio-padrão.

Quadro 2. Atributos químicos e físicos dos solos dos ambientes tabuleiro, carrasco,tabuleiro misto e espigão, na camada de 0 a 20 e 20 a $40 \mathrm{~cm}$ de profundidade

\begin{tabular}{|c|c|c|c|c|c|c|c|c|c|c|c|c|c|c|c|c|}
\hline \multirow{3}{*}{$\begin{array}{l}\text { Atributo do solo } \\
\text { pH em água }\end{array}$} & \multicolumn{4}{|c|}{ Tabuleiro } & \multicolumn{4}{|c|}{ Carrasco } & \multicolumn{4}{|c|}{ Tabuleiro misto } & \multicolumn{4}{|c|}{ Espigão } \\
\hline & \multicolumn{2}{|c|}{$0-20 \mathrm{~cm}$} & \multicolumn{2}{|c|}{$20-40 \mathrm{~cm}$} & \multicolumn{2}{|c|}{$0-20 \mathrm{~cm}$} & \multicolumn{2}{|c|}{$20-40 \mathrm{~cm}$} & \multicolumn{2}{|c|}{$0-20 \mathrm{~cm}$} & \multicolumn{2}{|c|}{$20-40 \mathrm{~cm}$} & \multicolumn{2}{|c|}{$0-20 \mathrm{~cm}$} & \multicolumn{2}{|c|}{$20-40 \mathrm{~cm}$} \\
\hline & $5,9^{(1)}$ & $\pm 0,4^{(2)}$ & 5,5 & $\pm 0,5$ & 5,6 & $\pm 0,2$ & 5,8 & $\pm 0,5$ & 5,6 & $\pm 0,8$ & 5,7 & $\pm 0,7$ & 5,0 & $\pm 0,6$ & 4,8 & $\pm 0,4$ \\
\hline$P\left(\mathrm{mg} \mathrm{dm}^{-3}\right)$ & 2,3 & $\pm 0,5$ & 2,0 & $\pm 0,8$ & 5,4 & $\pm 1,2$ & 5,8 & $\pm 2,1$ & 2,1 & $\pm 0,6$ & 2,2 & $\pm 0,9$ & 0,6 & $\pm 0,2$ & 0,6 & $\pm 0,2$ \\
\hline $\mathrm{Ca}\left(\mathrm{mmol}_{\mathrm{c}} \mathrm{dm}^{-3}\right)$ & 33,0 & $\pm 10,1$ & 29,0 & $\pm 12,1$ & 27,0 & $\pm 8,3$ & 28,0 & $\pm 9,2$ & 29,0 & $\pm 9,6$ & 22,0 & $\pm 11,2$ & 10,0 & $\pm 2,1$ & 8,0 & $\pm 2,1$ \\
\hline $\mathrm{Mg}\left(\mathrm{mmol}_{\mathrm{c}} \mathrm{dm}^{-3}\right)$ & 17,0 & $\pm 7,2$ & 15,0 & $\pm 6,3$ & 10,0 & $\pm 3,8$ & 9,0 & $\pm 1,5$ & 13,0 & $\pm 5,1$ & 11,0 & $\pm 4,1$ & 1,4 & $\pm 0,6$ & 1,0 & $\pm 0,3$ \\
\hline $\mathrm{K}\left(\mathrm{mmol}_{\mathrm{c}} \mathrm{dm}^{-3}\right)$ & 3,3 & $\pm 0,6$ & 4,0 & $\pm 0,5$ & 1,7 & $\pm 0,3$ & 1,9 & $\pm 0,8$ & 3,5 & $\pm 1,2$ & 3,6 & $\pm 0,7$ & 0,4 & $\pm 0,2$ & 0,33 & $\pm 0,1$ \\
\hline $\mathrm{Al}\left(\mathrm{mmol}_{\mathrm{c}} \mathrm{dm}^{-3}\right)$ & 0 & 0 & 0 & 0 & 0 & 0 & 0 & 0 & 0 & 0 & 0 & 0 & 8,0 & 0,5 & 10,0 & 1,5 \\
\hline $\mathrm{H}+\mathrm{Al}\left(\mathrm{mmol}_{\mathrm{c}} \mathrm{dm}^{-3}\right)$ & 42,0 & $\pm 11,8$ & 35,0 & $\pm 13,1$ & 33,0 & $\pm 8,9$ & 27,0 & $\pm 9,5$ & 46,0 & $\pm 14,2$ & 41,0 & $\pm 12,5$ & 47,2 & $\pm 14,4$ & 38,4 & $\pm 10,2$ \\
\hline $\mathrm{SB}\left(\mathrm{mmol}_{\mathrm{c}} \mathrm{dm}^{-3}\right)$ & 53,3 & $\pm 14,2$ & 48,0 & $\pm 10,2$ & 38,7 & $\pm 7,9$ & 38,9 & $\pm 10,8$ & 45,5 & $\pm 13,4$ & 36,6 & $\pm 10,9$ & 15,4 & $\pm 5,3$ & 12,3 & $\pm 4,2$ \\
\hline $\mathrm{t}\left(\mathrm{mmol}_{\mathrm{c}} \mathrm{dm}^{-3}\right)$ & 53,3 & $\pm 15,3$ & 48,0 & $\pm 16,1$ & 38,7 & $\pm 9,8$ & 38,9 & $\pm 8,7$ & 45,5 & $\pm 16,2$ & 36,6 & $\pm 9,8$ & 23,4 & $\pm 9,8$ & 22,3 & $\pm 8,2$ \\
\hline $\mathrm{m}(\%)$ & 0 & 0 & 0 & 0 & 0 & 0 & 0 & 0 & 0 & 0 & 0 & 0 & 34,0 & $\pm 10,2$ & 45,0 & $\pm 12,1$ \\
\hline $\mathrm{T}\left(\mathrm{mmol}_{\mathrm{c}} \mathrm{dm}^{-3}\right)$ & 95,3 & $\pm 31,8$ & 83,0 & $\pm 25,6$ & 71,7 & $\pm 25,1$ & 65,9 & $\pm 17,5$ & 91,5 & $\pm 26,6$ & 77,6 & $\pm 28,2$ & 62,6 & $\pm 17,2$ & 50,7 & $\pm 18,1$ \\
\hline $\mathrm{V}(\%)$ & 56,0 & $\pm 20,4$ & 58,0 & $\pm 18,4$ & 54,0 & $\pm 16,4$ & 59,0 & $\pm 15,4$ & 50,0 & $\pm 17,8$ & 47,0 & $\pm 17,4$ & 25,0 & $\pm 8,9$ & 24,0 & $\pm 7,4$ \\
\hline Mat. Org. ( $\mathrm{g} \mathrm{kg}^{-1}$ ) & 37,0 & $\pm 12,6$ & 21,0 & $\pm 9,5$ & 45,0 & $\pm 11,5$ & 27,0 & $\pm 10,6$ & 33,0 & $\pm 8,5$ & 28,0 & $\pm 9,8$ & 29,0 & $\pm 11,3$ & 22,0 & $\pm 8,9$ \\
\hline Areia $\left(\mathrm{g} \mathrm{kg}^{-1}\right)$ & 540,0 & $\pm 44,8$ & 520,0 & $\pm 43,4$ & 580,0 & $\pm 55,6$ & 530,0 & $\pm 65,8$ & 610,0 & $\pm 5,7$ & 580,0 & $\pm 4,5$ & 600,0 & $\pm 6,5$ & 570,0 & $\pm 64,5$ \\
\hline Silte $\left(\mathrm{g} \mathrm{kg}^{-1}\right)$ & 120,0 & $\pm 25,7$ & 110,0 & $\pm 35,2$ & 120,0 & $\pm 34,8$ & 130,0 & $\pm 33,4$ & 120,0 & $\pm 35,8$ & 100,0 & $\pm 23,4$ & 120,0 & $\pm 2,9$ & 130,0 & $\pm 32,4$ \\
\hline Argila $\left(\mathrm{g} \mathrm{kg}^{-1}\right)$ & 340,0 & $\pm 22,6$ & 370,0 & $\pm 24,2$ & 300,0 & $\pm 20,1$ & 340,0 & $\pm 28,2$ & 270,0 & $\pm 28,9$ & 320,0 & $\pm 25,1$ & 280,0 & $\pm 23,5$ & 300,0 & $\pm 26,8$ \\
\hline
\end{tabular}

${ }^{(1)}$ Média . ${ }^{(2)}$ Desvio-padrão.

ambientes identificados, são distróficos e com baixa disponibilidade de P (Quadro 1) e a vegetação é a de Cerrado típico (Scolforo \& Carvalho, 2006). Segundo Haridasan (1992), raramente os Cerrados ocorrem em solos com altos teores de $\mathrm{Ca}$ e $\mathrm{Mg}$, tendo algumas espécies melhor crescimento e desenvolvimento em solos com teores mais elevados de $\mathrm{Al}$ trocável.
Quanto ao Sistema de Capacidade de Uso, as terras da chapada foram classificadas como IVs, c, de acordo com as quadros 1 e 3 -terras passíveis de utilização com culturas anuais e perenes apenas ocasionalmente, mas adaptadas para pastagens e, ou, reflorestamento e, ou, vida silvestre, com limitações decorrentes da pequena capacidade de retenção de água (solos 
Quadro 3. Informações dos solos dos diferentes ambientes percebidos pelos agricultores e extrativistas

\begin{tabular}{|c|c|c|c|c|c|c|c|}
\hline Atributo & Baixa & Vereda & Chapada & Tabuleiro & Carrasco & $\begin{array}{c}\text { Tabuleiro } \\
\text { misto }\end{array}$ & Espigão \\
\hline $\begin{array}{l}\text { Profundidade } \\
\text { efetiva }^{(1)}\end{array}$ & $\begin{array}{l}\text { Não } \\
\text { identificada }\end{array}$ & $\begin{array}{l}\text { Não } \\
\text { identificada }\end{array}$ & $\begin{array}{l}\text { Não } \\
\text { identificada }\end{array}$ & $\begin{array}{l}\text { Não } \\
\text { identificada }\end{array}$ & $\begin{array}{l}\text { Não } \\
\text { identificada }\end{array}$ & $\begin{array}{l}\text { Não } \\
\text { identificada }\end{array}$ & $\begin{array}{l}\text { Profunda a } \\
\text { moderadamente } \\
\text { profunda }(0,5 \text { a } \\
2 \mathrm{~m})\end{array}$ \\
\hline Drenagem $^{(2)}$ & $\begin{array}{l}\text { Moderadamente } \\
\text { drenada a mal } \\
\text { drenada }\end{array}$ & Bem drenada & Bem drenada & Bem drenada & Bem drenada & Bem drenada & $\begin{array}{l}\text { Moderadamente } \\
\text { drenada }\end{array}$ \\
\hline Pedregosidade & Não pedregosa & Não pedregosa & Não pedregosa & Não pedregosa & $\begin{array}{l}\text { Com poucas } \\
\text { pedras (menos } \\
\text { de } 15 \% \text { da } \\
\text { massa do solo } \\
\text { em volume) }\end{array}$ & $\begin{array}{l}\text { Com poucas } \\
\text { pedras (menos } \\
\text { de } 15 \% \text { da } \\
\text { massa do solo } \\
\text { em volume) }\end{array}$ & $\begin{array}{l}\text { Abundante (15 } \\
\text { a } 50 \% \text { em } \\
\text { volume da } \\
\text { massa de solo) }\end{array}$ \\
\hline $\begin{array}{l}\text { Riscos de } \\
\text { inundação }\end{array}$ & $\begin{array}{l}\text { Freqüente e } \\
\text { média }^{(3)}\end{array}$ & Não há & Não há & Não há & Não há & Não há & Não há \\
\hline Declividade $^{(4)}$ & 0 a $5 \%$ & 2 a $5 \%$ & 0 a $10 \%$ & 5 a $15 \%$ & 5 a $10 \%$ & 5 a $15 \%$ & 5 a $45 \%$ \\
\hline $\begin{array}{l}\text { Erosão } \\
\text { hídrica }\end{array}$ & $\begin{array}{l}\text { Presente, mas } \\
\text { em grau não } \\
\text { identificado }\end{array}$ & Não aparente ${ }^{5}$ & Não aparente ${ }^{(5)}$ & Não aparente ${ }^{(5)}$ & Não aparente ${ }^{(5)}$ & Não aparente ${ }^{(5)}$ & $\begin{array}{l}\text { Laminar ligeira } \\
\text { e sulcos } \\
\text { ocasionais } \\
\text { superficiais }\end{array}$ \\
\hline $\operatorname{Cor}^{(6)}$ & 10YR 2/1, úmido & 10YR 4/4, úmido & 5 YR 5/8, úmido & 5 YR 5/8, úmido & 5YR $3 / 4$, úmido & 5 YR $5 / 6$, úmido & 5 YR $3 / 4$, úmido \\
\hline Textura $^{(7)}$ & Média & Média & Média & Média & Média & Média & Média \\
\hline $\begin{array}{l}\text { Saturação por } \\
\text { bases }{ }^{(7)}\end{array}$ & 64 \% (eutrófico) & 60 \% (eutrófico) & $\begin{array}{l}31 \% \\
\text { (distrófico) }\end{array}$ & 56 \% (eutrófico) & $54 \%$ (eutrófico) & 50 \% (eutrófico) & $25 \%$ (distrófico) \\
\hline $\begin{array}{l}\text { Classe de } \\
\text { capacidade de } \\
\text { uso }\end{array}$ & IIc & IIIc & IVs,c & IIIc & IIIc & IIIc & VIs, c \\
\hline
\end{tabular}

(1) Observada em cortes de barrancos. ${ }^{(2)}$ Inferida através da profundidade do lençol freático, evidência de mosqueados e gleização e textura da camada de $0-40 \mathrm{~cm}$ de profundidade. ${ }^{(3)}$ Ocorre entre 1 e 5 anos, permanecendo o solo coberto com água por mais de um mês. ${ }^{(4)}$ Determinada por clinômetro. ${ }^{(5)}$ Solos virgens recobertos por vegetação. (6) De acordo com a Carta de Munsell.

${ }^{(7)}$ Referente à camada de $0-20 \mathrm{~cm}$ de profundidade.

arenosos), da baixa fertilidade dos solos e da seca prolongada.

Os solos do tabuleiro e do tabuleiro misto são semelhantes: apresentam textura média, com teores mais elevados de argila que os dos demais ambientes (Quadros 2 e 3). São eutróficos, destacando-se os teores elevados de K e baixos de P (Quadro 2). A vegetação do tabuleiro foi classificada como de Cerrado denso e a do tabuleiro misto como um mosaico constituído por Cerrado denso e floresta decídua, que é uma Caatinga arbórea denominada "mata seca" (Scolforo \& Carvalho, 2006). De acordo com os quadros 2 e 3, as terras do ambiente tabuleiro foram classificadas como IIIc, conforme o Sistema de Capacidade de Uso, semelhantemente as terras da vereda.

A diferença na fitofisionomia dos ambientes conhecidos por baixa e tabuleiro, que apresentam disponibilidade de nutrientes às plantas semelhantes (Quadros 1 e 2), pode ser explicada possivelmente pela acumulação de nutrientes por meio da lixiviação e transporte durante a formação da paisagem e a história de desenvolvimento dos solos e da vegetação no passado. Também Nogueira \& Haridasan (1997) observaram que as matas de galeria do Planalto Central brasileiro que ocorrem em solos mesotróficos e distróficos apresentam maiores teores de nutrientes foliares do que a vegetação de Cerrado das redondezas. Por outro lado, segundo van den Berg (1995), a umidade do solo é o principal fator que influencia a distribuição da vegetação, sendo as propriedades químicas mais um produto do que uma causa da cobertura vegetal, embora possam tornar as diferenças na vegetação marcantes.

Em relação à chapada, outro ambiente que faz limite com o tabuleiro, pode-se inferir que a maior disponibilidade de nutrientes, principalmente $\mathrm{K}$ e, provavelmente, a maior retenção de água pelos solos dos tabuleiros explicam as diferenças fitofisionômicas entre esses dois ambientes. O maior teor de $\mathrm{K}$ nos solos do tabuleiro pode ser explicado pela provável lixiviação e transporte desse elemento da área de chapada pelas água pluviais. Haridasan (1992) verificou diferenças entre as comunidades de cerradões em solos distróficos e mesotróficos; entretanto, não observou diferenças significativas entre Cerrado e cerradões nas mesmas condições de fertilidade do solo, concluindo que cerradões em solos distróficos 
estabelecem-se quando os solos ainda poderiam fornecer nutrientes em quantidades maiores para o estabelecimento de uma biomassa maior. Segundo Ribeiro \& Walter (1998), as diferenças fitofisionômicas podem ser explicadas pela movimentação temporal dos mosaicos da vegetação do Cerrado, relacionadas com os fatores antrópicos, como freqüência de queimadas, pastejo, aberturas de áreas agropecuárias, retirada seletiva de madeira e queimadas para manejo e pastagem.

O carrasco ocorre em solos eutróficos, com baixa disponibilidade de P (Quadro 2). A vegetação foi classificada como de floresta decídua, conforme Scolforo \& Carvalho (2006). Em relação aos demais ambientes descritos anteriormente observam-se teores mais elevados de Ca no solo (Quadro 2). As terras desse ambiente, de acordo com os quadros 2 e 3 , foram classificadas como IIIc, no Sistema de Capacidade de Uso, semelhantemente às terras da vereda e do tabuleiro.

Os solos do tabuleiro misto apresentam atributos semelhantes aos do tabuleiro típico. A ocorrência de espécies vegetais distintas, típicas de tabuleiro e de carrasco em um mesmo ambiente, como ocorre no tabuleiro misto, pode ser atribuída à indiferença dessas espécies pelas condições de solo. Segundo Ratter et al. (1978), há espécies vegetais que ocorrem somente em solos ácidos, outras são restritas aos solos calcários e outras são indiferentes.

O ambiente espigão apresenta solos distróficos, com baixa disponibilidade de $\mathrm{P}$ e com teores de argila semelhantes aos do carrasco (Quadro 2). Há limitações pela pedregosidade excessiva e pela pequena profundidade efetiva (Quadro 3). A vegetação foi classificada como Cerrado aberto de acordo com Scolforo \& Carvalho (2006). Quanto ao Sistema de Capacidade de Uso, as terras foram classificadas como VIs,c - terras impróprias para cultivos intensivos, mas ainda adaptadas para pastagens e, ou, reflorestamento e, ou, vida silvestre, com limitações devidas ao relevo fortemente inclinado, pedregosidade abundante, pequena capacidade de retenção de água, baixa fertilidade dos solos e seca prolongada.

\section{Relação entre os usos das terras indicados pe- los agricultores e extrativistas e pelo Sistema de Capacidade de Uso e parcelamento da área}

Verificaram-se semelhanças entre os usos indicados pelos agricultores e extrativistas e aos do Sistema de Capacidade de Uso para os ambientes: baixa, vereda e espigão.

Para o ambiente tabuleiro, tabuleiro misto e carrasco, o uso das terras segundo os agricultores e extrativistas foi mais amplos que o Sistema de Capacidade de Uso, uma vez que, no enquadramento no Sistema de Capacidade de Uso, a declividade do terreno foi fator determinante do uso das terras, enquanto em sistemas agroecológicos, em que se utilizam práticas de conservação do solo e exploração pouco intensiva das terras, esse fator não teve a mesma importância. Segundo os agricultores e extrativistas, esses ambientes podem ser utilizados com culturas anuais e perenes, graças à boa disponibilidade de nutrientes às plantas e à retenção de água no solo por longo período após o termino da estação chuvosa. Já para o Sistema de Capacidade de Uso, esses ambientes são passíveis de utilização apenas com pastagem e, ou, reflorestamento e, ou, vida silvestre em razão da seca prolongada.

Por outro lado, para o ambiente chapada, o uso indicado pelos agricultores e extrativistas, considerando as limitações de fertilidade do solo, foi mais restrito que o do Sistema de Capacidade de Uso. Para os agricultores e extrativistas, as terras do ambiente chapada prestam-se apenas para a criação extensiva de animais domésticos e extrativismo das plantas nativas, por não serem feitas correções e pela valorização cultural e econômica atribuídas às espécies vegetais nativas desse ambiente. Já para o Sistema de Capacidade de Uso, as terras da chapada são passíveis de cultivos ocasionalmente, em virtude da facilidade de eventuais correções de deficiências ou desequilíbrios de nutrientes (Lepsch, 1983).

Utilizando as informações de uso e manejo das terras, procedeu-se à elaboração do parcelamento em: setenta e seis (76) lotes familiares com área média de 72,5 ha (área total de 5.510 ha); áreas de manejo agroextrativista (total de 7.965,2 ha) e áreas de reserva legal (4.626,9 ha) (Figura 4). As áreas de preservação permanente, conforme legislação vigente, estão incluídas nas áreas dos lotes familiares e agroextrativistas, quando pertinentes (Figura 4).

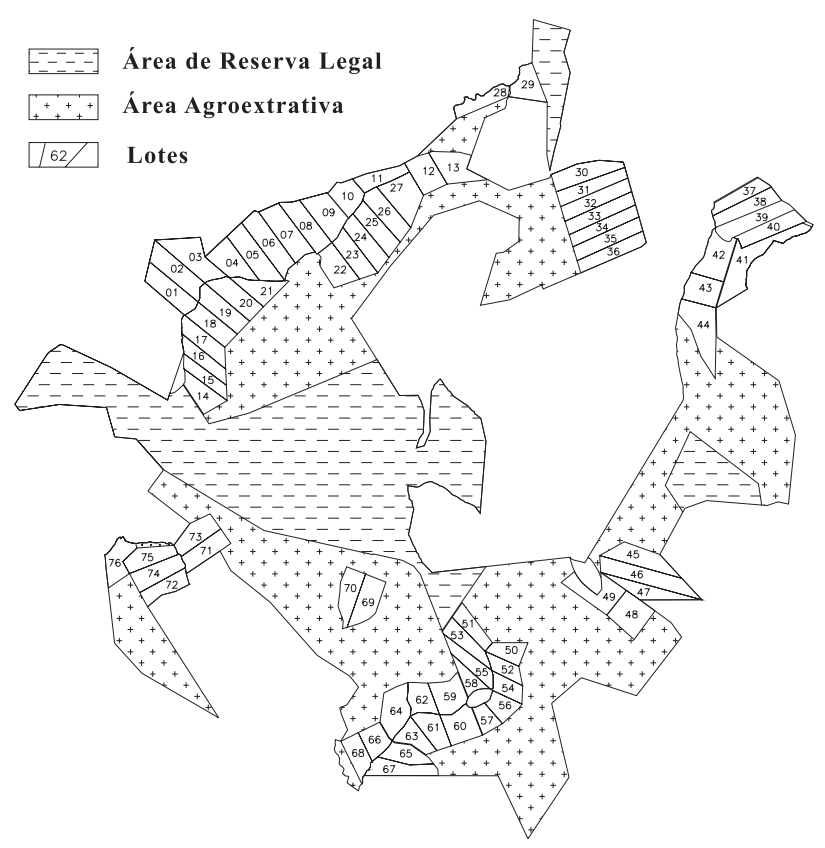

Figura 4. Distribuição das áreas dos Lotes familiares, Reserva Legal e Agroextrativista do Projeto de Assentamento Americana. 
Os lotes familiares são áreas destinadas às moradias e instalação dos sistemas produtivos e correspondem a $30 \%$ da área do PA. De modo geral, os lotes foram divididos tendo como referência que todos teriam acesso às terras de cultura, compreendidas por áreas de baixa e de tabuleiro. Os lotes que tiveram terrenos com menor percentagem de terras de cultura foram parcialmente compensados com áreas maiores.

As áreas de reserva legal e permanente constituem meio de garantir, pelo menos parcialmente, os ciclos ecológicos e a perpetuação de espécies da fauna e flora. Neste sentido, estaria garantido o estoque de biodiversidade funcional que poderia transbordar para os lotes individuais, contribuindo para a regulação de prováveis erupções populacionais de espécies com potencial de tornarem-se pragas. No levantamento da flora nas áreas de reserva, foram identificadas 76 espécies arbóreas e, no da fauna, 129 espécies de aves, sendo duas ameaçadas de extinção na região: Capacetinho-do-oco-de-pau (Poospiza cinerea) e o Azulinho (Porphyrospiza caerulescens) (Machado et al., 1998), ambas endêmicas do Cerrado (Silva, 1995). Em relação aos mamíferos, duas espécies encontradas são ameaçadas de extinção: o veado-campeiro (Ozotocerus bezoarticus) e a suçuarana (Puma concolor) (Machado et al., 1998).

\section{CONCLUSÕES}

1. Os ambientes reconhecidos pelos agricultores e extrativistas foram: baixada, vereda, chapada, tabuleiro, carrasco, tabuleiro misto e espigão.

2. O conhecimento local sobre o uso das terras teve estreita relação com o Sistema de Capacidade de Uso, constituindo uma ferramenta para o parcelamento das áreas com limitações edafoclimáticas para fins de reforma agrária.

\section{AGRADECIMENTOS}

Ao Instituto Nacional de Colonização e Reforma Agrária, Superintendência Regional 06, pelo apoio financeiro, e aos moradores do Projeto de Assentamento Americana, pelas informações imprescindíveis à realização deste trabalho.

\section{LITERATURA CITADA}

ALVARES V., V.H.; NOVAIS, R.F.; BARROS, N.F.; CANTARUTTI, R.B. \& LOPES, A.S. Interpretação dos resultados das análises de solos. In: RIBEIRO, A.C.; GUIMARÃES, P.T.G. \& ALVAREZ V., V.H., orgs Recomendações para o uso de corretivos e fertilizantes em Minas Gerais - 5a. Aproximação. 5.ed. Viçosa, MG, Comissão de Fertilidade do Solo do Estado de Minas Gerais, 1999. p.25-32.
BERTOLINI, D. \& BELLINAZZI JÙNIOR, R. Levantamento do meio físico para determinação da capacidade de uso das terras. 2.ed. Campinas, CATI, 1994. 29p. (CATI. Boletim Técnico, 175)

CORREIA, J.B. Pedologia e conhecimento local: Proposta metodológica de interlocução entre os saberes construídos por pedólogos e agricultores em área de Cerrado em Rio Pardo de Minas, MG. Seropédica, Universidade Federal Rural do Rio de Janeiro, 2005. 234p. (Tese de Doutorado)

COSTA, J.B.A. Cultura, natureza e populações tradicionais: O Norte de Minas como síntese da nação brasileira. R. Verde Grande, 1:8-47, 2006.

DAYRELL, C.A. Geraiszeiros y biodivesidad em el Norte de Minas Gerais: La contribuición de la agroecologia y la etnoecologia em los estúdios de los agroecossistemas. Huelva, Universidad Nacional de Andalúcia, 1998. 195p. (Tese de Mestrado)

EMPRESA BRASILEIRA DE PESQUISA AGROPECUÁRIA EMBRAPA. Centro Nacional de Pesquisa de Solos. Sistema brasileiro de classificação de solos. Brasília, Embrapa Produção de Informação, 1999. 412p.

EMPRESA BRASILEIRA DE PESQUISA AGROPECUÁRIA EMBRAPA. Serviço Nacional de Levantamento e Conservação de Solos. Levantamento exploratório: Reconhecimento de solos do Norte de Minas Gerais: área de atuação da SUDENE. Recife, 1979. 407p. (Boletim Técnico, 60; SUDENE - DRN. Série Recursos de Solos, 12)

EMPRESA BRASILEIRA DE PESQUISA AGROPECUÁRIA EMBRAPA. Serviço Nacional de Levantamento e Conservação de Solo. Manual de métodos de análise de solo. Rio de Janeiro, Ministério da agricultura, 1997. 212p.

HARIDASAN, M. Observations on soils, foliar nutrient concentrations and floristic composition of Cerrado and Cerradão communities in Central Brazil. In. PROCTOR, J.; RATTER, J.A. \& FURLEY, P.A., eds. The nature and dynamics of forest-savanna boundaries. Londres, Chapman Hall, 1992. p.171-184.

KRASILNIKOV, P.V. \& TABOR, J.A. .Perspective on utilitarian ethnopedology. Geoderma, 111:197-215, 2003.

LEPSCH, I.P. Manual para levantamento utilitário do meio físico e classificação de terras no sistema de capacidade de uso: $4^{\mathrm{a}}$ aproximação. Campinas, Sociedade Brasileira de Ciência do Solo, 1983. 175p.

MACHADO, A.B.M.; FONSECA, G.A.R.B.; MACHADO, L.M.; AGUIAR, S. \& LINS, L.V. Livro vermelho das espécies ameaçadas de extinção da fauna de Minas Gerais. Belo Horizonte, Minas Gerais, Fundação Biodiversitas, 1998. 608 p.

NEUMANN, P.S. \& LOCH, C. Legislação ambiental, desenvolvimento rural e práticas agrícolas. Ci. Rural, 32:243-249. 2002.

NOGUEIRA, P.E. \& HARIDASAN, M. Foliar nutrient concentrations of tree species in four gallery forest in central Brazil. In: ENCINAS, J.I. \& KLEIN, C., eds. INTERNATIONAL SYMPOSIUM ON ASSESSMENT AND MONITORING OF FOREST IN TROPICAL DRY REGIONS WITH SPECIAL REFERENCE TO GALLERY FOREST, Brasília, 1997. Proceedings. Brasília, Universidade de Brasília, 1997. p.309-321. 
RATTER, J.A.; RICHARDS, P.W.; ARGENT, G. \& GIFFORD, D.R. Observations on the forest of some mesotrophic soils in Central Brazil. R. Bras. Bot., 1:47-58, 1978.

RIBEIRO, J.F. \& WALTER, B.M.T. Fitofisionomias do bioma Cerrado. In. SANO, S.M. \& ALMEIDA, S.P., eds. Cerrado: ambiente e flora.Planaltina, Embrapa-CPAC, 1998. p.89-166.

SCOLFORO, J.R.S. \& CARVALHO, L.M.T. Mapeamento e inventário da flora nativa e dos reflorestamentos de Minas Gerais. Lavras, Universidade Federal de Lavras, 2006. 288 p.

SILVA, J.M.C. Biogeographic analysis of the South American Cerrado avifauna. Steenstrupia, 21:49-67, 1995.
TRINDADE, L.S. \& LAPLATINE, F. O que é imaginário. São Paulo, Brasiliense, 1997. 82p.

van den BERG, E. Estudo florístico e fitossociológico de uma floresta ripária em Itutinga, MG e análise das correlações entre variáveis e a distribuição das espécies de porte arbóreo-arbustivo. Lavras, Universidade Federal de Lavras, 1995. 73p. (Tese de Mestrado)

VIANA, H.S.; BRITO, R.M.D.A.; FELIPE, A.J. \& RIOS, M.V. Projeto cadastro de abastecimento por águas subterrâneas, Estados de Minas Gerais e Bahia: Diagnóstico do município de Grão-Mogol, MG. Belo Horizonte, Companhia de Pesquisa de Recursos Minerais, 2004. 71p. 